\title{
A novel chlorhexidine-hexametaphosphate coating for titanium with antibiofilm efficacy and stem cell cytocompatibility
}

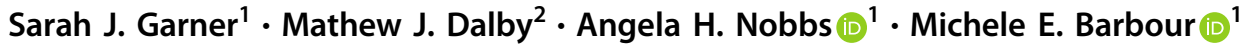

Received: 30 June 2021 / Accepted: 3 October 2021 / Published online: 20 November 2021

(c) The Author(s) 2021

\begin{abstract}
Dental implants are an increasingly popular way to replace missing teeth. Whilst implant survival rates are high, a small number fail soon after placement, with various factors, including bacterial contamination, capable of disrupting osseointegration. This work describes the development of chlorhexidine-hexametaphosphate coatings for titanium that hydrolyse to release the antiseptic agent chlorhexidine. The aim was to develop a coating for titanium that released sufficient chlorhexidine to prevent biofilm formation, whilst simultaneously maintaining cytocompatibility with cells involved in osseointegration. The coatings were characterised with respect to physical properties, after which antibiofilm efficacy was investigated using a multispecies biofilm model, and cytocompatibility determined using human mesenchymal stem cells. The coatings exhibited similar physicochemical properties to some implant surfaces in clinical use, and significantly reduced formation of multispecies biofilm biomass up to $72 \mathrm{~h}$. One coating had superior cytocompatibility, with mesenchymal stem cells able to perform normal functions and commence osteoblastic differentiation, although at a slower rate than those grown on uncoated titanium. With further refinement, these coatings may have application in the prevention of bacterial contamination of dental implants at the time of surgery. This could aid a reduction in rates of early implant failure.
\end{abstract}

\section{Graphical Abstract}
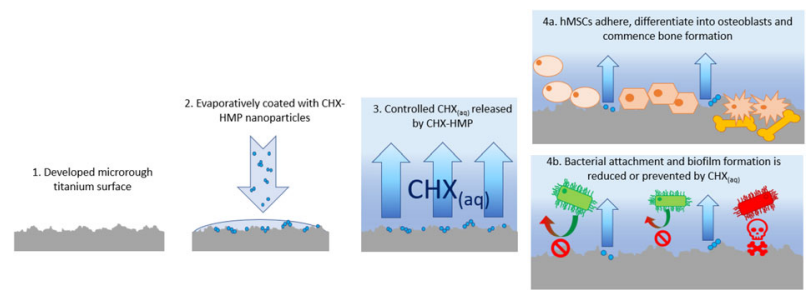

Supplementary information The online version contains supplementary material available at https://doi.org/10.1007/s10856021-06616-5.

Angela H. Nobbs

angela.nobbs@bristol.ac.uk

$\triangle$ Michele E. Barbour

m.e.barbour@bristol.ac.uk

1 Bristol Dental School, University of Bristol, Lower Maudlin Street, Bristol BS1 2LY, UK

2 Centre for Cell Engineering, Institute of Molecular Cell and Systems Biology, University of Glasgow, Joseph Black Building, University Avenue, Glasgow G12 8QQ, UK

\section{Introduction}

Dental implants are used to rehabilitate patients with congenital or acquired missing teeth. Following surgical placement into alveolar bone, implants are colonised by osteoblasts and undergo osseointegration. Their popularity is continually increasing [1], since they often allow a fixed rather than removable prosthesis and can reduce the need for hard or soft tissue support required by conventional prostheses. However, they are not without problems, one being failure of osseointegration immediately following surgery $[2,3]$. Various factors have been associated with this, including peri-operative bacterial contamination of the implant, suboptimal patient response, and iatrogenic issues [4-9].

The oral environment is host to a wide range of microorganisms which form a complex ecosystem, with microbial 
species interacting with one another as well as with the oral soft and hard tissues. While the presence of microorganisms and of biofilm is inevitable, it is important to manage overall bacterial load as well as the presence and prevalence of particular pathogens to ensure continued good oral health. There is a high chance of peri-operative bacterial contamination from various sources [10]. Bacteria readily adhere to roughened implant surfaces $[11,12]$ and can form biofilms, which disrupt osseointegration of the implant by mesenchymal stem cells (MSCs). This has been hypothesised as one cause of early implant failures [8]. Whilst these early failures have a lower incidence $(1.7-4 \%$ of implants; $[2,3])$ compared to late failures (1-47\%; [13-15]), they render an implant unusable and can result in substantial bone loss, thus limiting or complicating future treatment. Prevention of bacterial contamination at the time of implant placement is therefore desirable, and could contribute to reduced failure rates [16].

Research in the field of implant dentistry to prevent early failures currently centres on maximising the rate and quality of osseointegration and preventing bacterial contamination. The use of antibiotics in prevention of postoperative implant infection is debatable $[17,18]$, and in a climate of increasing antimicrobial resistance, alternative means to address this should be investigated. Current strategies showing promise in prevention of biofilm formation on implant surfaces are based around three approaches: changes to surface topography to prevent bacterial adhesion, surfaces that release antimicrobial agents for a defined period to prevent adhesion and kill bacteria in the vicinity, and surfaces with permanently bonded antimicrobial agents that prevent attachment of bacteria to the surface in the long term [19, 20].

The aim of this work was to develop a novel coating for a dental implant-like surface using a slow-release compound for the antimicrobial agent chlorhexidine ( $\mathrm{CHX})$ in the form of a previously developed hexametaphosphate salt (CHXHMP) [21, 22]. CHX-HMP is a novel salt of the common antiseptic CHX, which is more commonly encountered as the CHX digluconate or diacetate salts. The HMP salt of $\mathrm{CHX}$ has a much lower solubility in aqueous solution than the digluconate or diacetate salts and dissolves slowly on contact with water, thus releasing the $\mathrm{CHX}$ gradually over an extended period. A more extensive discussion of $\mathrm{CHX}$ HMP, its preparation and characteristics can be found elsewhere [22]. The rate and magnitude of $\mathrm{CHX}$ release from CHX-HMP functionalised materials depends on multiple factors including the local conditions, the doping of CHX-HMP and the matrix in which the CHX-HMP is embedded; the release duration may be days, weeks, months or years [23-26]. In this study, CHX-HMP was further explored as a coating for a titanium substrate and subjected to testing to determine physical characteristics, antibiofilm efficacy and cytocompatibility.

\section{Materials and methods}

\subsection{CHX-HMP coatings}

Detailed description of the method for production of a sandblasted acid etched (SLA) surface on commercially pure titanium coupons to produce substrates for deposition of CHX-HMP is described in Supplementary Data 1. Briefly, titanium coupons (Ti-Tek (UK) Limited, Birmingham, UK) were sandblasted with $50 \mu \mathrm{m} \mathrm{Al}_{2} \mathrm{O}_{3}$ particles (Henry Schein ${ }^{\circledR}$ Inc., Melville, USA) followed by a $24 \mathrm{~h}$ etch in $2 \mathrm{M}$ sulfuric acid (ThermoFisher Scientific, Loughborough, UK), with an acid change at $16 \mathrm{~h}$ (SLA Ti surface) and cleaning with sonication in a soap solution.

A chlorhexidine-hexametaphosphate suspension (CHXHMP) was precipitated in deionised water (DIW) containing $0.3125 \%$ dissolved poloxamer 407 (P407) by addition of aqueous solutions sodium hexametaphosphate and then chlorhexidine digluconate under rapid stirring. This resulted in formation of a white precipitate: CHX-HMP. P407 was used to reduce $\mathrm{CHX}$-HMP particle aggregation. The suspension was diluted 100-fold in DIW and aliquots (100 or $200 \mu \mathrm{L})$ were deposited onto SLA Ti coupons and allowed to dry before a washing step in DIW and dry storage (coated substrates denoted CHX-HMP-100 and CHX-HMP-200). A negative control was produced using SLA Ti coupons immersed in stirring DIW for $30 \mathrm{~min}$, denoted SLA Ti henceforth.

\subsection{Characterisation of coated SLA Ti}

Methods to characterise the CHX-HMP coated SLA Ti are described in Supplementary Data 2: Methods to characterise CHX-HMP coated SLA Ti. This included contact angle and surface roughness measurements, and scanning electron microscopy (SEM) for plain imaging and with energy dispersive X-ray analysis (EDX). Additionally, release of aqueous chlorhexidine $\left(\mathrm{CHX}_{(\mathrm{aq})}\right)$ from $\mathrm{CHX}-\mathrm{HMP}$ coated substrates was calculated using elution into a simulated tissue fluid (STF, physiologic simulation) or $2 \mathrm{M}$ hydrochloric acid (total available $\mathrm{CHX}_{(\mathrm{aq})}$ ), measurement with spectrophotometry at $255 \mathrm{~nm}$ and comparison with known standards.

\subsection{Development of biofilm model}

To enable testing of the antibiofilm efficacy of the CHX-HMP coatings, a multispecies biofilm model was developed, adapted from that described by Millhouse et al. [27], and organisms selected due to their association with peri-implant disease [10, 28-31]. The bacterial strains used are listed in Table 1. All were grown and maintained under anaerobic conditions (10\% hydrogen, $10 \%$ carbon dioxide and $80 \%$ nitrogen at $45 \%$ humidity at $37^{\circ} \mathrm{C}$ ), with all experimental work carried out under the same, except where explicitly stated. 
Table 1 Bacterial strains used in this work

\begin{tabular}{llll}
\hline Strain ID & Species & Site of isolation & Source \\
\hline UB2182 & $\begin{array}{l}\text { Aggregatibacter actinomycetemcomitans ATCC } \\
\text { 43718 (serotype b) }\end{array}$ & $\begin{array}{l}\text { Subgingival } \\
\text { dental plaque }\end{array}$ & {$[60]$} \\
UB2296 & Fusobacterium nucleatum & Peri-implantitis lesion & {$[61]$} \\
UB5 & Porphyromonas gingivalis & Periodontal pocket & Laboratory stock \\
UB1 & Prevotella nigrescens & Periodontal pocket & {$[62]$} \\
UB2281 & Streptococcus mitis & Peri-implantitis lesion & {$[61]$} \\
\hline
\end{tabular}

Detailed description of the selection and maintenance of bacterial strains, and development of the multispecies biofilm model are included in Supplementary Data 3: Bacterial strains, culture conditions and multispecies biofilm model development. Briefly, biofilms were formed at two different inocula $\left(0.5 \times 10^{7}\right.$ or $\left.0.5 \times 10^{4} \mathrm{CFU}\right)$ in nutrient rich media containing $2 \% \mathrm{v} / \mathrm{v}$ sterile-filtered human saliva (TSBYEHM $+\mathrm{S}$ ) (ethics approval South Central Oxford C Research Ethics, reference 08/H0606/87 +5).

Initially, $S$. mitis $\left(0.5 \mathrm{~mL}, 0.5 \times 10^{7}\right.$ or $\left.0.5 \times 10^{4} \mathrm{CFU}\right)$ was added to substrates and incubated under anaerobic conditions for $24 \mathrm{~h}$. After removal of spent medium and gentle washing, F. nucleatum was added at the same CFU. The plate was incubated for a further $24 \mathrm{~h}$ before removal of spent medium, washing and addition of A. actinomycetemcomitans, $P$. gingivalis and $P$. nigrescens at the same CFU. Coupons were incubated for a further $24 \mathrm{~h}$, resulting in a biofilm grown over $72 \mathrm{~h}$ containing five species.

A modification to the model was later introduced to clarify the mechanism by which the CHX-HMP coatings affected biomass formation: this consisted of addition of $S$. mitis at time 0 and at $24 \mathrm{~h}$ (same CFU), followed by inoculation of $F$. nucleatum at $48 \mathrm{~h}$ and $A$. actinomycetemcomitans, $P$. gingivalis and $P$. nigrescens at $72 \mathrm{~h}$ to give a biofilm grown over $96 \mathrm{~h}$.

\subsection{Antibiofilm efficacy of CHX-HMP coatings}

The antibiofilm efficacy of the CHX-HMP coatings compared to SLA Ti (positive control) was assessed using biomass assays and quantitative PCR (qPCR). Detail of these methods, including qPCR primers used, is contained in Supplementary Data 4: Methods to assess antibiofilm efficacy of CHX-HMP coatings.

\subsection{Cytocompatibility testing}

Evaluation of the cytocompatibility of the CHX-HMP coatings was conducted in vitro using human mesenchymal stromal cells (hMSCs) (Promocell, Germany). Methods employed were SEM imaging, phosphate staining, immunostaining for tubulin, vinculin, osteopontin and osteocalcin, and metabolomic analysis. Details of methods for each of these, alongside cell culture and maintenance, is included in Supplementary Data 5: Cytocompatibility testing methods.

\subsection{Statistical analyses}

Statistical analyses for all data (except metabolomics work) were carried out using IBM SPSS Statistics Version 24 (IBM, New York, USA). Data were checked for normality and homogeneity of variance using Shapiro-Wilk and Levene tests. For all tests, $p$ values of $<0.05$ were considered to indicate statistical difference. For normally distributed data with homogeneity of variance, a Student's $t$-test ( 2 independent variables) or a 1-way ANOVA (3 or more independent variables) was employed to determine statistical difference, followed by Sidak correction for multiple comparisons, and Tukey's Honestly Significant Difference (HSD) test used post hoc to identify differences. Where data were normally distributed but did not have homogeneity of variance, a 1-way Welch ANOVA was performed.

Statistical analysis of metabolomics data was performed in Ingenuity Pathway Analysis software (Qiagen) and Metaboanalyst software and consisted of calculation of a $z$ score to indicate a predicted pathway activation or deactivation ( $z$-scores $>$ or $<2$ respectively) with Fisher's Exact where indicated, and 1-way ANOVA or Kruskal Wallis followed by Fisher's LSD post hoc in Metaboanalyst. Principal Component Analysis (PCA) plots were also performed for each surface for various metabolomic functions. Significance was assumed for all test results of $p<0.05$.

\section{Results}

\subsection{CHX-HMP coatings}

The mean contact angle and surface roughness (as $R_{\mathrm{a}}$ ) for SLA Ti, CHX-HMP-100 and CHX-HMP-200 surfaces are shown in Table 2. Statistical analysis demonstrated no difference in contact angle between SLA Ti and CHX-HMP coated samples. All surfaces exhibited a slight hydrophilic tendency $\left(<90^{\circ}\right.$ contact angle). There were no statistical differences between $R_{\mathrm{a}}$ values measured in the $X$ and $Y$ directions for all coatings indicating surfaces were isotropic (Table 2). There were no statistical differences in $R_{\mathrm{a}}$ value between SLA Ti and CHX-HMP-100 $(p=0.279)$ or CHXHMP-200 ( $p=0.068$ ) coating (Table 2). However, CHXHMP-100 and CHX-HMP-200 were statistically different 
Table 2 Physical and chemical characteristics of SLA Ti and CHX-HMP coatings

\begin{tabular}{|c|c|c|c|}
\hline & SLA Ti & CHX-HMP-100 & CHX-HMP-200 \\
\hline Mean contact angle (SD) & $84^{\circ}\left(7.28^{\circ}\right)$ & $82^{\circ}(5.95)$ & $82^{\circ}(6.58)$ \\
\hline $\begin{array}{l}\text { Mean surface roughness- } R_{\mathrm{a}}(\mathrm{SD})[P \text {-value } \\
\text { for } R_{\mathrm{a}} \text { in } X \text { and } Y \text { directions on surface } \\
\text { (Student's } t \text { test)] }\end{array}$ & $\begin{array}{l}1.25 \mu \mathrm{m} \\
(0.06 \mu \mathrm{m})[0.214]\end{array}$ & $\begin{array}{l}1.31 \mu \mathrm{m} \\
(0.08 \mu \mathrm{m})[0.356]\end{array}$ & $\begin{array}{l}1.16 \mu \mathrm{m}^{*} \\
(0.04 \mu \mathrm{m})[0.098]\end{array}$ \\
\hline Chlorine peaks present in EDX & Absent & $\mathrm{K}_{\alpha} 1$ and $\mathrm{K}_{\alpha} 2$ & $\mathrm{~K}_{\alpha} 1$ and $\mathrm{K}_{\alpha} 2$ \\
\hline Phosphorus peaks present in EDX & Absent & $\mathrm{K}_{\alpha} 1$ and $\mathrm{K}_{\alpha} 2$ & $\mathrm{~K}_{\alpha} 1$ and $\mathrm{K}_{\alpha} 2$ \\
\hline
\end{tabular}

$S D$ standard deviation

${ }^{*} p=0.01$ relative to CHX-HMP-100, as determined by one way ANOVA and Tukey HSD post hoc $(n=8)$

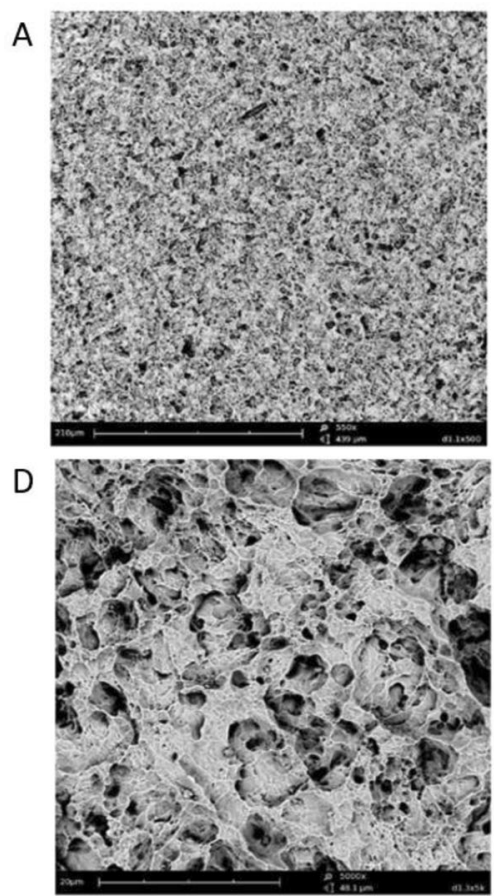

SLA Ti

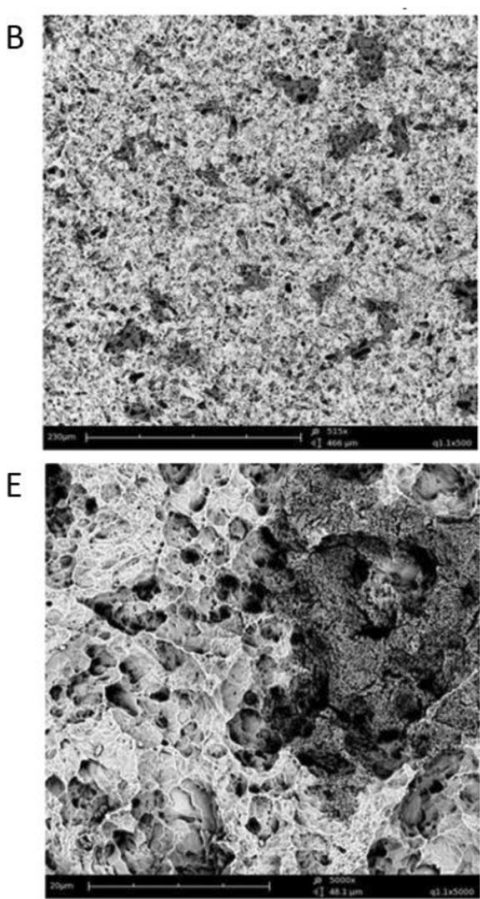

CHX-HMP-100

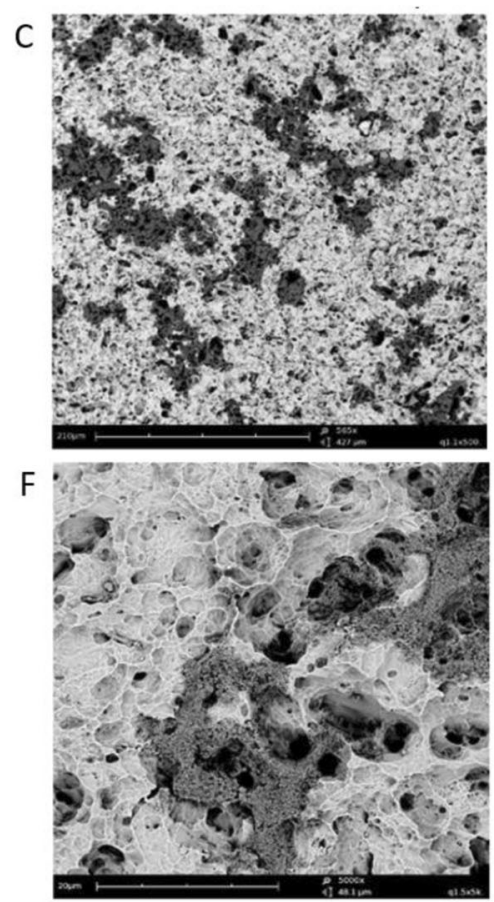

CHX-HMP-200

Fig. 1 Representative SEM micrographs of A, D SLA Ti, B, E CHX-HMP-100, and C, F CHX-HMP-200 coatings showing number and distribution of CHX-HMP deposits. Scale bars $210 \mu \mathrm{m}(\mathbf{A}-\mathbf{C})$ and $20 \mu \mathrm{m}(\mathbf{D}-\mathbf{F})$

from one another $(p=0.01$; all one way ANOVA and Tukey HSD post hoc; $n=8$ ).

SEM imaging demonstrated the surface morphology of the developed SLA Ti surface, and the discontinuous deposition of CHX-HMP deposits on the two different coatings (Fig. 1). Composition of the deposits was confirmed using SEM-EDX analysis (Table 2), including presence of chlorine and phosphorous, which are present in the CHX-HMP structure [32]. A greater number of larger deposits were seen on the CHX-HMP-200 coating.

Elution studies in STF showed most of the $\mathrm{CHX}_{(\mathrm{aq})}$ release from CHX-HMP coated substrates occurred over the first $7 \mathrm{~h}$ (Fig. 2). A separate 14 day elution demonstrated no further substantial $\mathrm{CHX}_{(\mathrm{aq})}$ release (Supplementary Data 6: $\mathrm{CHX}_{(\mathrm{aq})}$ elution into STF over 14 days). In the presence of
$2 \mathrm{M} \mathrm{HCl}$, all available $\mathrm{CHX}_{(\mathrm{aq})}$ was immediately released from both CHX-HMP coatings (Fig. 2). The mean total available $\mathrm{CHX}_{(\mathrm{aq})}$ released from the CHX-HMP-100 and CHX-HMP-200 coatings was 106 and $156 \mu$ moles $/ \mathrm{m}^{2}$, respectively, resulting in equivalent concentrations of $0.001 \%(21.2 \mu \mathrm{M})$ and $0.0015 \%(31.2 \mu \mathrm{M})$.

\subsection{Antibiofilm efficacy of CHX-HMP coatings}

A 5-species biofilm model was used to determine antimicrobial efficacy of the CHX-HMP coatings. A steady increase in biofilm biomass formation over $72 \mathrm{~h}$ was seen on SLA Ti. By contrast, less biomass formed on both CHXHMP coatings at both $0.5 \times 10^{4}$ and $0.5 \times 10^{7} \mathrm{CFU}$ inocula (Fig. 3A, B). A $96 \mathrm{~h}$ biofilm model was also employed to 
Fig. 2 Mean cumulative $\mathrm{CHX}_{(\mathrm{aq})}$ release per metre squared of CHX-HMP coated SLA Ti. Elution into STF at room temperature. Error bars show standard deviation. Dotted lines represent pooled mean total available $\mathrm{CHX}$ on each coating type as determined using elution into $2 \mathrm{M} \mathrm{HCl}(10$ specimens per coating type)

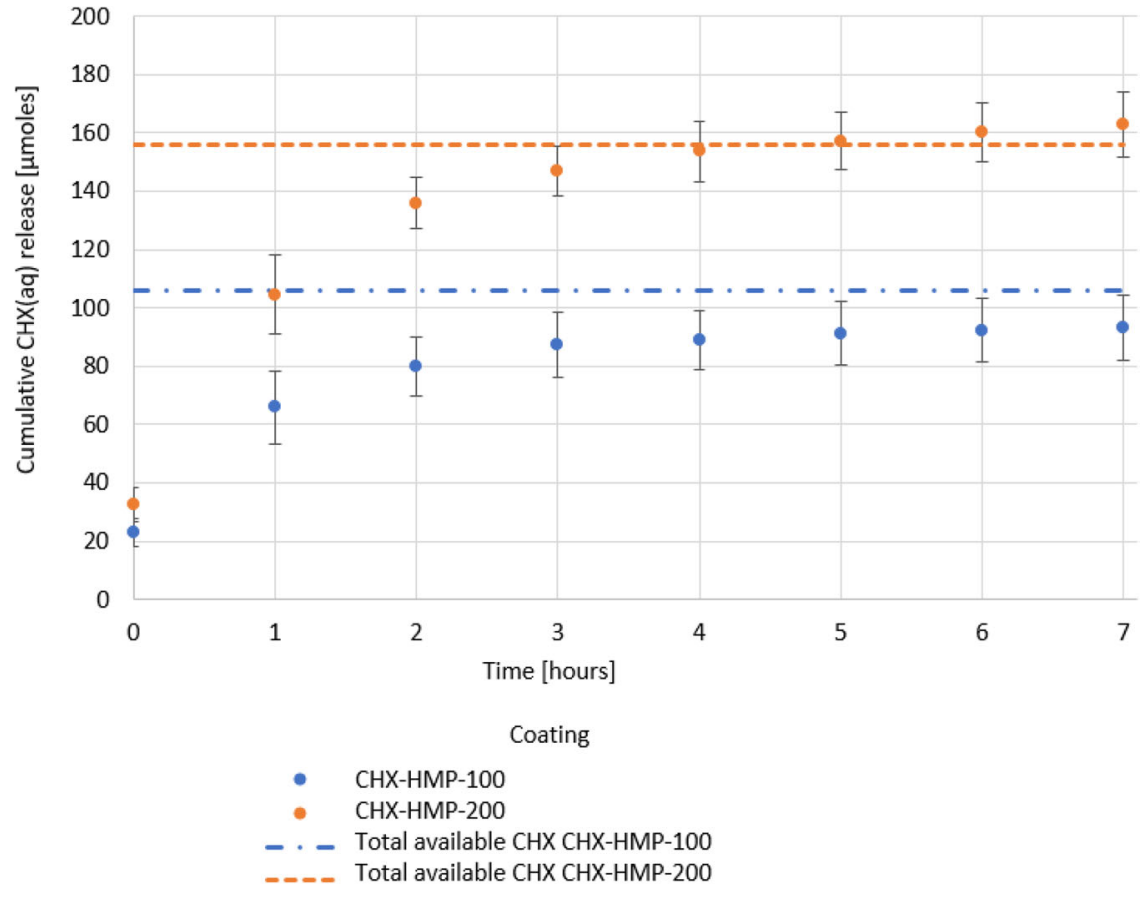

clarify the mechanism by which the CHX-HMP coatings affected biomass formation; by adding a second inoculation of $S$. mitis at $24 \mathrm{~h}$, it was possible to ascertain the antibiofilm effect of the CHX-HMP coatings persisted beyond $24 \mathrm{~h}$ and a medium change. Results of this model showed less biomass was found on the CHX-HMP coated substrates at 24 and $48 \mathrm{~h}$ at the $0.5 \times 10^{4}$ inoculum compared to SLA Ti control (Fig. 3C). At the higher $0.5 \times 10^{7}$ inoculum, however, there were no significant differences in biomass between SLA Ti and the CHX-HMP coatings at any time point (Fig. 3D).

Table 3 shows the results of qPCR analysis of biofilm composition after $72 \mathrm{~h}$ on control and test substrates. There were no statistical differences to biofilm composition, regardless of presence or absence of CHX-HMP. $S$. mitis was the predominant organism, constituting 95.6-99.9\% of the biofilms formed. The remaining four species each made up less than $1 \%$ of the biofilm in most instances.

\subsection{Cytocompatibility testing}

Cytocompatibility testing was performed over 1-28 days to determine hMSC response to the CHX-HMP coatings with respect to survival, attachment, growth, proliferation, metabolism and differentiation. This facilitated a more complete understanding of the mechanisms by which released $\mathrm{CHX}_{(\mathrm{aq})}$ exerted cytotoxic effects, and the likely sequalae of these, allowing assessment of the potential suitability of the CHXHMP coatings for use on dental implants.
SEM imaging demonstrated ready adherence and growth of hMSCs on SLA Ti (Fig. 4A, D). On the CHX-HMP-100 coating, cells were fewer, smaller and more spaced, some with a stellate morphology, whilst others were spherical (Fig. 4B, E). On the CHX-HMP-200 coating, fewer cells were present still, with a larger number exhibiting a spherical, unspread morphology (Fig. 4C, F). Vinculin immunostaining demonstrated larger, more frequent focal adhesions in hMSCs grown on SLA Ti compared to either of the CHX-HMP coatings. The reduction in adhesion was most notable for hMSCs on the CHX-HMP-200 coating (Fig. 4G-I).

Tubulin immunostaining demonstrated large, active tubulin networks on hMSCs grown on SLA Ti (Fig. 5A). hMSC cells and their associated tubulin networks were smaller and less organised on the CHX-HMP-100 coating and showed no organisation for cells on the CHX-HMP-200 coating (Fig. 5B-C), with close spacing of DAPI-stained nuclei suggestive of diminutive cells growing in close association or on top of each other.

After 21 days' growth, composite micrographs showed a confluent layer of hMSCs present on SLA Ti, with numerous deposits of green coloured osteocalcin and osteopontin visible throughout (Fig. 5D, G). Cells were far less frequent and more spaced out on the CHX-HMP-100 coating, and fewer deposits of osteocalcin and osteopontin were present (Fig. 5E, H). Very few cells were present on the CHX-HMP-200 coatings, which were smaller and with altered morphology compared to SLA Ti and CHX-HMP100 , with no osteocalcin deposits and only very infrequent deposits of osteopontin (Fig. 5F, I). 
A

1

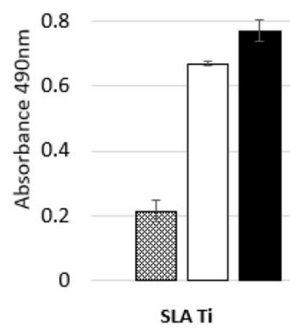

C

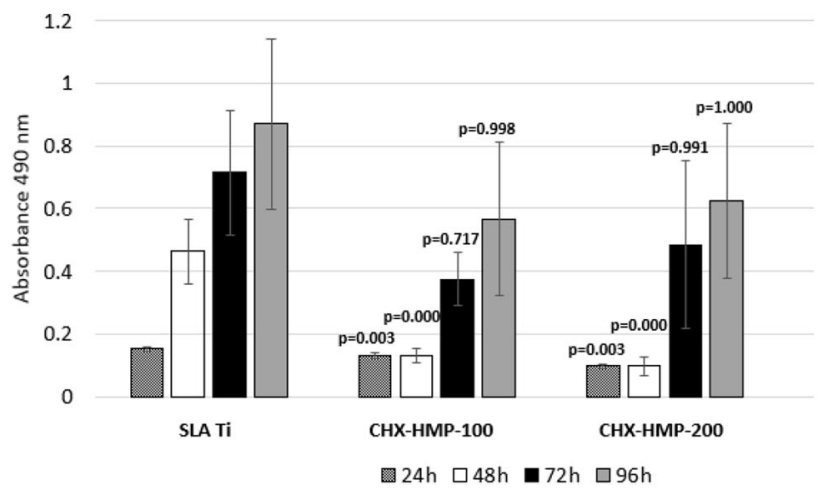

Fig. 3 Biomass of biofilms grown on uncoated and CHX-HMP coated SLA Ti. Biofilms were formed using bacterial inocula of $0.5 \times 10^{4}$ $\mathrm{CFU}(\mathbf{A}, \mathbf{C})$ or $0.5 \times 10^{7} \mathrm{CFU}(\mathbf{B}, \mathbf{D})$, and grown for $72 \mathrm{~h}(\mathbf{A}, \mathbf{B})$ or $96 \mathrm{~h}(\mathbf{C}, \mathbf{D})$, the latter including a re-inoculation step with $S$. mitis after

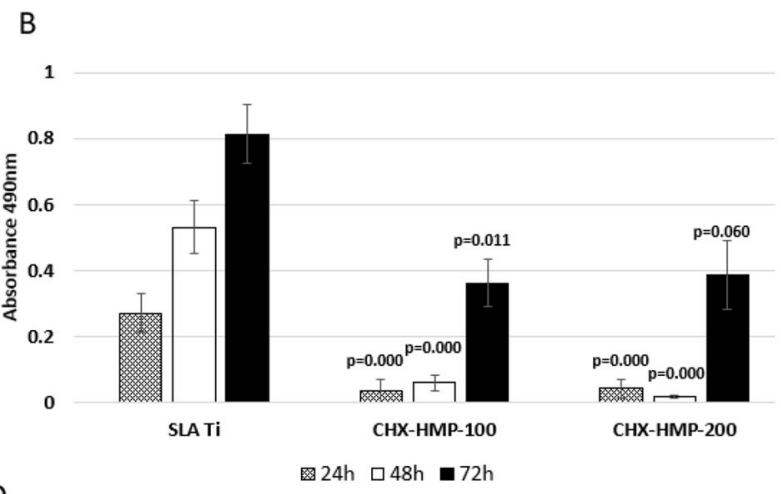

D

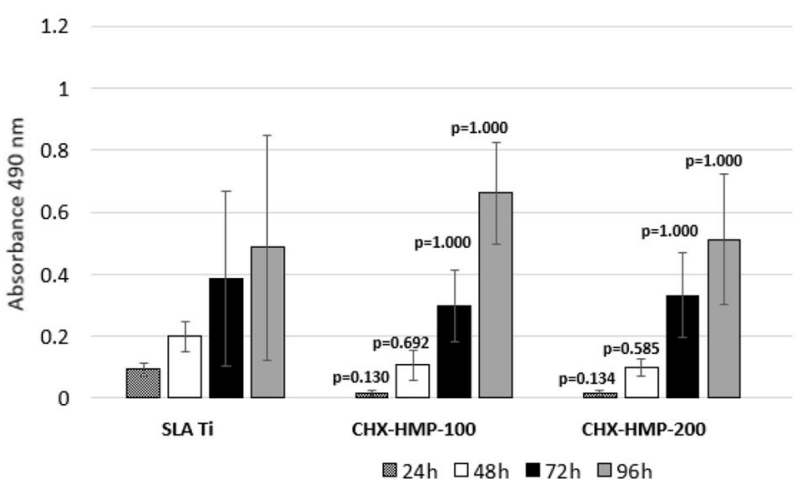

$24 \mathrm{~h}$. Biomass was quantified by safranin stain and acetic acid release. Error bars represent standard deviations. $P$-values are shown relative to SLA Ti surface as determined by 1-way ANOVA with Sidak correction post hoc $(n=3)$

Table 3 Mean percentage composition of 72-h multispecies biofilms formed on SLA Ti and CHX-HMP coatings

\begin{tabular}{|c|c|c|c|c|c|}
\hline \multirow[b]{2}{*}{ Coating and inoculum } & \multicolumn{5}{|c|}{ Mean $\%$ of each species within total biofilm ${ }^{a}$} \\
\hline & S. mitis & F. nucleatum & A. actinomycetemcomitans & P. gingivalis & P. nigrescens \\
\hline SLA Ti: $0.5 \times 10^{4}$ inoculum & $99.93(0.12)$ & $0.06(0.12)$ & $0.00(0.00)$ & $0.00(0.00)$ & $0.00(0.00)$ \\
\hline SLA Ti: $0.5 \times 10^{7}$ inoculum & $98.41(1.41)$ & $0.95(0.96)$ & $0.09(0.10)$ & $0.02(0.02)$ & $0.53(0.49)$ \\
\hline CHX-HMP-100: $0.5 \times 10^{4}$ inoculum & $98.26(2.34)$ & $0.53(0.54)$ & $0.23(0.45)$ & $0.00(0.00)$ & $0.98(1.96)$ \\
\hline CHX-HMP-100: $0.5 \times 10^{7}$ inoculum & $98.82(0.41)$ & $0.49(0.27)$ & $0.09(0.06)$ & $0.04(0.02)$ & $0.56(0.53)$ \\
\hline CHX-HMP-200: $0.5 \times 10^{4}$ inoculum & $98.73(1.25)$ & $1.47(1.86)$ & $0.24(0.35)$ & $0.01(0.02)$ & $0.38(0.67)$ \\
\hline CHX-HMP-200: $0.5 \times 10^{7}$ inoculum & $95.57(3.84)$ & $0.67(0.73)$ & $2.51(4.57)$ & $0.04(0.05)$ & $1.20(1.62)$ \\
\hline
\end{tabular}

${ }^{a}$ Percentage composition by gDNA mass. Figures in brackets indicate standard deviation. No significant differences between coating type or inocula for any species, as determined by 1-way ANOVA with Sidak post hoc $(n=4)$

After 28 days, phosphate deposits were seen on both SLA Ti and CHX-HMP-100, although the latter had fewer, whilst none were detected on CHX-HMP-200 (Fig. 5J-L).

Metabolomic analysis was undertaken on cells grown on SLA Ti+/- CHX-HMP coatings at 7 and 14 days. A PCA plot indicated that, in comparison to SLA Ti, hMSC responses were most different on the $\mathrm{CHX}_{(\mathrm{aq})}$ control (Fig. 6 pink and yellow) at both time points. Responses of hMSCs on both CHX-HMP coated surfaces were similar to control at day 7 but diverged more by 14 days of culture (Fig. 6).
From the same data, networks were produced for key cell pathways, and indicated significant activations or deactivations of relevant functions on CHX-HMP coatings compared to SLA Ti. Examples of these are presented in Supplementary Data 10.

A summary of key relevant predicted cell function changes (compared to SLA Ti at the corresponding time point) at 7 and 14 days formed from these networks, and metabolomic data analysis and computation of $z$-scores for each surface type, is given in Table 4 . All statistically data from this analysis are shown in Supplementary Data 9. 

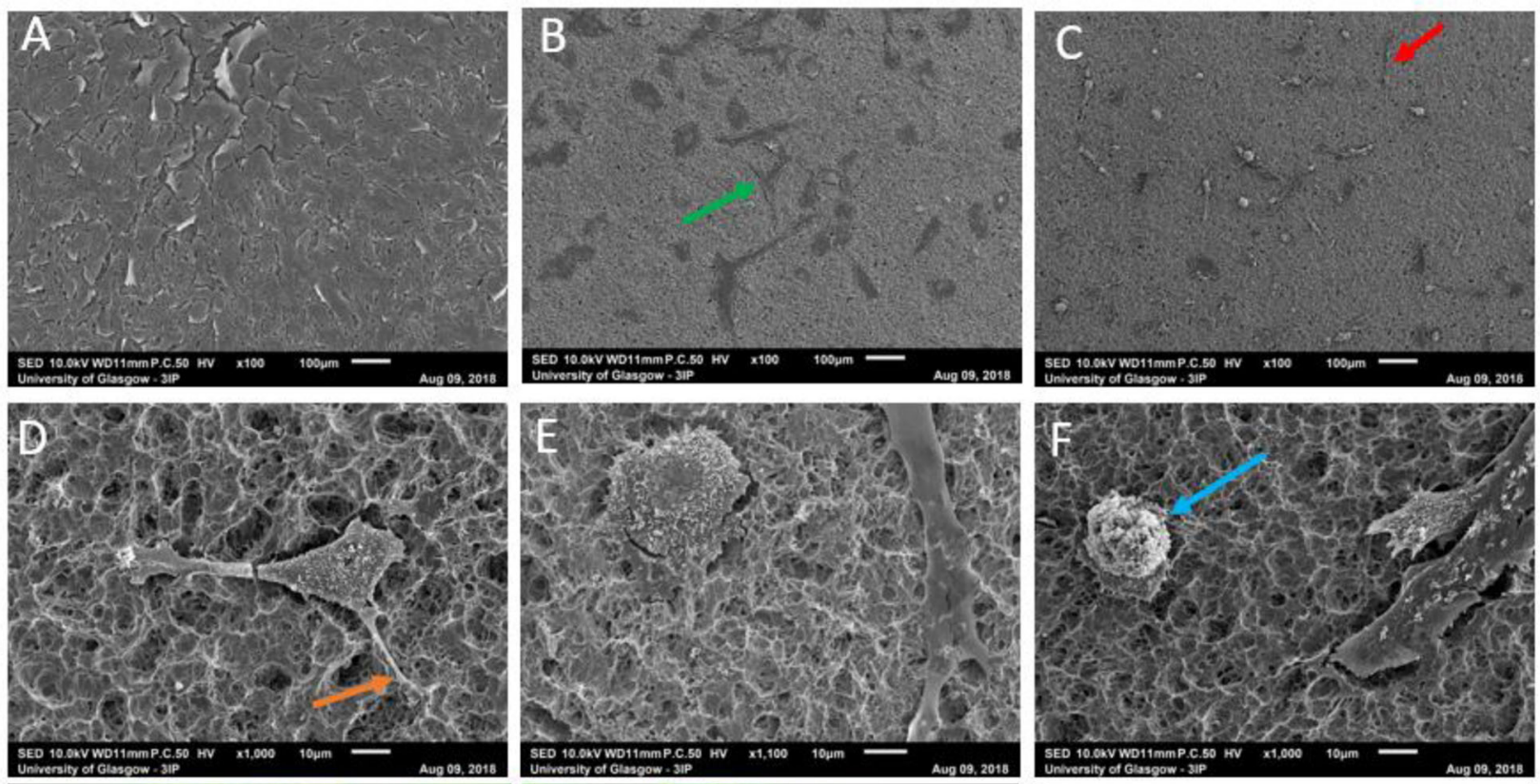

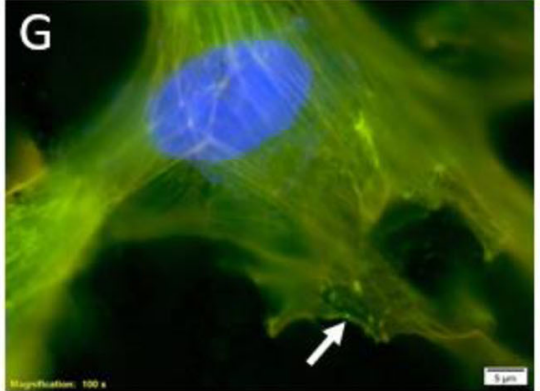

SLA Ti

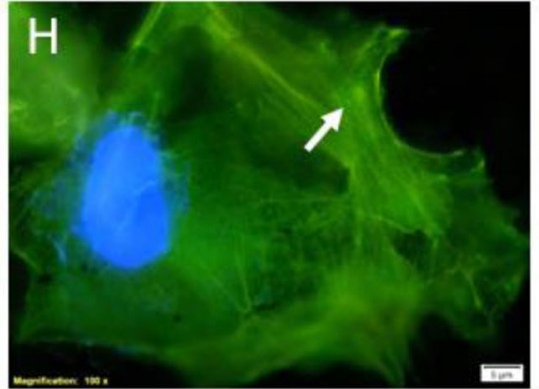

CHX-HMP-100

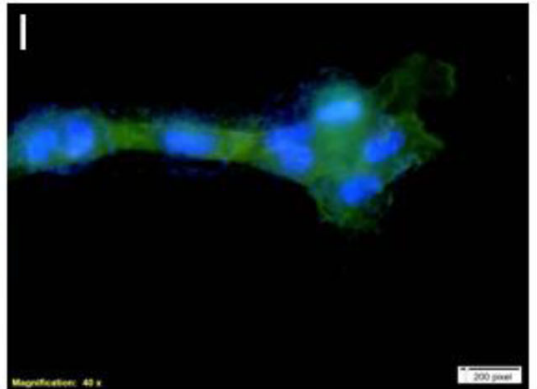

CHX-HMP-200
Fig. 4 Adhesion of hMSCs to SLA Ti and CHX-HMP coatings after 7 days' growth. SEM images (A-F) show different morphologies. Arrows: red-spindle shaped cells; green-stellate morphology; blue-spherical morphology; orange-cell processes interacting with

\section{Discussion}

A SLA type surface finish for titanium was selected for use in this work, since this is one of the most commonly used preparations for dental implants [33]. A technique for reliable production of this type of finish was devised that resulted in a surface with similar characteristics to those found on SLA type implant surfaces in research and clinical use [34, 35].

Characterisation by means of contact angle measurement and $R_{\mathrm{a}}$ indicated favourable surface properties: hydrophilicity of implant surfaces has been shown to increase adhesion of plasma proteins and favour blood clot retention $[1,36]$. Ultimately this results in higher bone to implant contact [37], favouring improved osseointegration [35, 38-40]. A moderately rough surface, as developed here [41], is also considered to favour osseointegration due to increased attachment of the blood clot and, later, of surface. Colour composite micrographs of vinculin immunostaining (G-I) show vinculin deposits (white arrows) within focal adhesions (green) and DAPI-stained nuclei (blue). Scale bars: A-C, $100 \mu \mathrm{m}$; D-F, $10 \mu \mathrm{m}$; G-I, $5 \mu \mathrm{m}$

osteoblast precursor cells and thus bone ingrowth [1, 33, 40, 42, 43]. Whilst many microscopically rough surfaces allow formation of undesirable bacterial biofilms [11, 12], an $R_{\mathrm{a}}$ of $1-2 \mu \mathrm{m}$ is considered to give the best compromise with regards to facilitating adhesion of hMSCs and ultimately osseointegration [41]. As such, the physical surface characteristics for the SLA Ti surfaces developed here could be expected to facilitate osseointegration.

$\mathrm{CHX}_{(\mathrm{aq})}$ elution kinetics into a physiological medium demonstrated that almost all $\mathrm{CHX}_{(\mathrm{aq})}$ release from the $\mathrm{CHX}$ HMP coatings occurred within the first $7 \mathrm{~h}$, and reached levels that exceeded the MIC for $\mathrm{CHXDG}_{(\mathrm{aq})}$ determined for each test bacterium (Supplementary Data 8: MIC and MBC to $\left.\mathrm{CHXDG}_{(\mathrm{aq})}\right)$. As a consequence, however, the majority of $\mathrm{CHX}_{(\mathrm{aq})}$ was removed at the first medium change $(24 \mathrm{~h})$ in the biofilm model. Nonetheless, the short-term inhibitory effects of $\mathrm{CHX}_{(\mathrm{aq})}$ on primary coloniser $S$. mitis still impacted subsequent biofilm formation, and the extent of 


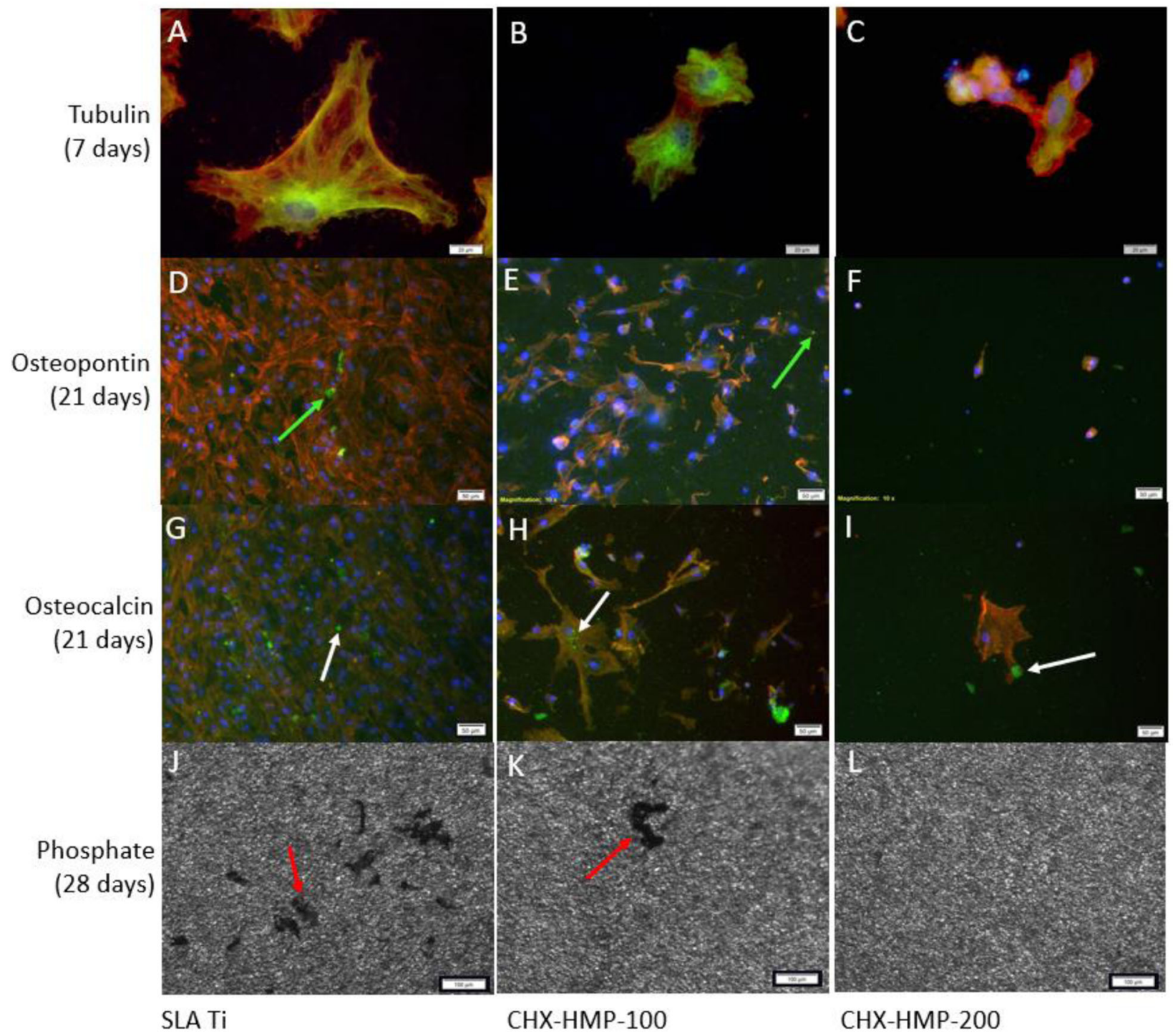

Fig. 5 Assessment of hMSC metabolism and differentiation after growth on SLA Ti, CHX-HMP-100, and CHX-HMP-200 coatings. Images $\mathbf{A}-\mathbf{C}$ are colour composite micrographs of hMSCs grown for 7 days showing tubulin staining of microtubule networks (green), nuclei (blue), and actin (red). Images D-F are colour composite micrographs of hMSCs grown for 21 days showing osteocalcin staining of calcified extracellular deposits (green arrows to green

these effects correlated with microbial burden. These findings are in accordance with the accepted biofilm model [44] in which adhesion of primary colonisers such as S.mitis are critical to subsequent attachment of bridging organisms and secondary colonisers: here, when the attachment of $S$. mitis was prevented, subsequent biomass accretion was significantly reduced.

When S. mitis was reinoculated at $24 \mathrm{~h}$ in the $96 \mathrm{~h}$ model, thus presumably negating the effect of released $\mathrm{CHX}_{(\mathrm{aq})}$ which had been removed during the medium change, the reduction in biomass on both CHX-HMP coatings persisted only as far as $48 \mathrm{~h}$ at the lower deposits), nuclei (blue), and actin (red). Images $\mathbf{G}-\mathbf{I}$ are colour composite micrographs of hMSCs grown for 21 days showing osteopontin staining of calcified extracellular deposits (white arrows to green deposits), nuclei (blue), and actin (red). Images $\mathbf{J}-\mathbf{L}$ are light micrographs showing silver stained deposits of phosphate (red arrows) produced by hMSCs grown for 28 days. Scale bars: A-C $20 \mu \mathrm{m}$, D-I $50 \mu \mathrm{m}, \mathbf{J}-\mathbf{L} 100 \mu \mathrm{m}$

inoculum. There was no significant difference in biomass seen at any timepoint on any surface for the higher inoculum in the $96 \mathrm{~h}$ model. These findings indicate that both duration of $\mathrm{CHX}_{(\mathrm{aq})}$ presence in the medium and microbial burden were important factors in the effect of the CHX-HMP coatings on biofilm growth, and that the effect on S. mitis of $\mathrm{CHX}_{(\mathrm{aq})}$ released from these coatings did not persist beyond $24 \mathrm{~h}$.

A similar elution profile and antibiofilm effect has been observed previously with nanoparticle encapsulated $\mathrm{CHX}_{(\mathrm{aq})}$. Seneviratne et al. [45] showed that whilst active $\mathrm{CHX}_{(\mathrm{aq})}$ release only occurred during the first $6 \mathrm{~h}$, this was adequate 
to suppress growth of a similar four-species anaerobic biofilm for up to $72 \mathrm{~h}$.

There were no significant differences in the composition of the biofilms formed here on SLA Ti compared to CHXHMP coated surfaces, with the primary coloniser $S$. mitis predominating. This is comparable to studies using similar models, with early coloniser species prevailing in multispecies, anaerobic biofilms [27, 46]. Streptococcus species are known to predominate in periodontal and peri-implant health [28, 47, 48], whilst in disease, their proportion is

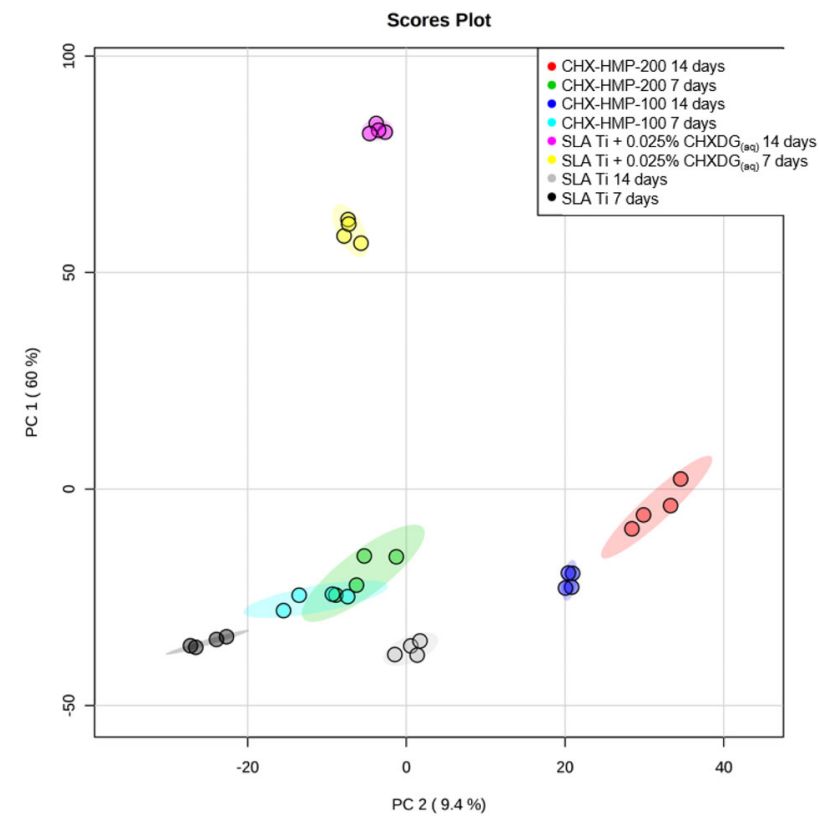

Fig. 6 Combined PCA plot for data on all surface types at both 7 and 14 days. Data has been $\log$ transformed to facilitate presentation, after normalisation to SLA Ti at 7 days $(n=1)$. Filled circles represent single specimens, shaded area represents region of $95 \%$ confidence interval. Key: CHX-HMP-200 14 days-red, 7 days-green; CHXHMP-100 14 days-dark blue, 7 days-light blue; SLA Ti $+0.025 \%$ $\mathrm{CHXDG}_{(\mathrm{aq})} 14$ days-pink, 7 days-yellow; SLA Ti 14 days-grey, 7 days-black. Cell responses were most different on SLA Ti + $0.025 \% \mathrm{CHXDG}_{(\mathrm{aq})}$ (pink and yellow) at both time points reduced [10]. It is therefore encouraging that the $\mathrm{CHX}$ HMP coatings did not alter the composition of the bacterial biofilm to a more pathogenic one. Since implants are ideally placed into a healthy oral environment, the model used here should mimic the conditions under which an implant surface might become contaminated during placement. Therefore, these data suggest that the $\mathrm{CHX}_{(\mathrm{aq})}$ release profile of the $\mathrm{CHX}-\mathrm{HMP}$ coatings has potential to prevent biofilm formation by bacterial species relevant to implant infection.

The $\mathrm{CHX}_{(\mathrm{aq})}$ release duration of these experimental coatings is nevertheless considerably shorter than those previously reported using the same CHX-HMP formulation [23-25] which have ranged from weeks to months. Here, CHX-HMP was deposited onto SLA Ti solely by evaporation, whereas in other studies, it was incorporated in substantial volumes into absorbent materials, either by prolonged immersion, solubilisation of the substrate or as a component of a dual-mix material. On SLA Ti, which has no known absorbent properties, it is unlikely that any CHX-HMP was physically retained within the material and so therefore, the small volume of ultimately soluble CHX-HMP which was deposited, hydrolysed rapidly on exposure to a dilute aqueous solution. However, as shown above, this modest release profile was adequate to suppress biomass accretion by inhibition of primary coloniser attachment and proliferation, most likely because the MIC for $S$. mitis was exceeded by the $\mathrm{CHX}_{(\mathrm{aq})}$ released from the CHX-HMP coatings.

Regarding potential future clinical application, cytocompatibility of the SLA Ti surface and CHX-HMP coating was an important consideration. SEM imaging demonstrated attachment to and proliferation of hMSCs on SLA Ti, with an abundance of large cells exhibiting a spread morphology. The presence of bright, dense tubulin networks indicated active intracellular transport and thus low levels of cell stress on this surface [49], whilst numerous focal adhesions suggested that SLA Ti would later stimulate
Table 4 Summary of significant changes to relevant hMSC functions on test surfaces at 7 and 14 days relative to SLA $\mathrm{Ti}$

\begin{tabular}{|c|c|c|c|c|c|c|}
\hline \multirow[t]{2}{*}{ Function/Network changes } & \multicolumn{2}{|c|}{ CHX-HMP-100 } & \multicolumn{2}{|c|}{ CHX-HMP-200 } & \multicolumn{2}{|c|}{$\begin{array}{l}\text { SLA Ti }+0.025 \% \\
\text { CHXDG }_{(\mathrm{aq})}\end{array}$} \\
\hline & 7 days & 14 days & 7 days & 14 days & 7 days & 14 days \\
\hline ALP activation & Activated & Deactivated & Activated & Deactivated & Activated & Deactivated \\
\hline Apoptosis & Activated & Deactivated & Activated & Activated & Activated & Activated \\
\hline $\mathrm{Ca}^{2+}$ mobilisation & NS & NS & NS & NS & Activated & Deactivated \\
\hline Mitochondrial dysfunction & Activated & Deactivated & Activated & NS & NS & NS \\
\hline Necrosis & Activated & Deactivated & Activated & Activated & Activated & Activated \\
\hline Generation of ROS & Activated & NS & Activated & Deactivated & NS & Activated \\
\hline
\end{tabular}

Statistically significant changes to cell functions on each test surface compared to SLA Ti at same time point are shown. NS - no significant difference compared to SLA Ti control at same time point. Results are predicted changes to functional networks, based on $z$-scores from metabolomic analysis (Supplementary Data 9) 
hMSC osteogenic differentiation via activation of ERK1/2 and phosphorylation of RUNX2 [50]. This was further supported by extensive osteocalcin and osteopontin immunostaining and the presence of calcium phosphate at 28 days on SLA Ti, confirming late-stage osteoblastic differentiation. Such observations are in agreement with other titanium surfaces with similar $R_{\mathrm{a}}$ values [42, 51].

SEM, vinculin and tubulin staining on cells grown on CHX-HMP coatings in this work demonstrated reduced attachment of hMSCs, smaller cells with altered morphology, reduced numbers of focal adhesions and evidence of altered metabolism, similar to changes seen in osteoblast-like cells exposed to $\mathrm{CHX}_{(\mathrm{aq})}$ in other studies [52-54]. Vinculin is a membrane protein associated with cell adhesion to a surface, and is involved in linkage of integrin adhesion molecules to the actin cytoskeleton. The presence and size of labelled vinculin gives qualitative information on cell adhesion to a surface. When integrins interact with the extracellular matrix, phosphorylation of Rho-associated protein kinase (ROCK) and myosin light chain kinase (MLCK) occurs, causing contraction of the cell cytoskeleton, and groups of integrins form cell adhesions containing vinculin. Formation of these adhesions causes an intracellular signalling cascade and these cytoskeletal signalling events have been shown to play a key role in deciding MSC fate. Tubulin is a component of the cytoskeleton, and the metabolism of the cell can be inferred from a tubulin immunostain. Microtubules are involved in multiple transport pathways within the cell thus, the density of the tubulin networks qualitatively indicates more or less cell activity. A rounded cell morphology was suggestive of apoptosis or irreversible cell damage, attributable to the presence of $\mathrm{CHX}_{(\mathrm{aq})}[52,55]$, and a dose-response effect to CHX-HMP was apparent, similar to that observed with $\mathrm{CHX}$ (aq) $[52,56]$. These findings imply that the CHX-HMP coatings assessed here disrupted cells by a similar mechanism to that reported previously.

$\mathrm{CHX}_{(\mathrm{aq})}$ exerts cytotoxic effects via multiple mechanisms including reduction in mitochondrial membrane potential, ATP depletion, increased cytoplasmic $\mathrm{Ca}^{2+}$ concentration and increased generation of reactive oxygen species (ROS), resulting in apoptosis and necrosis $[52,53,55,57,58]$. The severity of these effects is dependent on exposure duration, concentration, $\mathrm{CHX}_{(\mathrm{aq})}$ release rate and the presence of cytoprotective factors such as FBS [52, 53, 57, 58].

Metabolomic data collected from hMSCs grown for 7 days on CHX-HMP coatings predicted cytotoxic effects, with activation of apoptosis and necrosis signalling, increased ROS production and increased mitochondrial dysfunction, indicative of cell stress, as has been observed previously $[52,57,59]$. By 14 days after the $\mathrm{CHX}_{(\mathrm{aq})}$ present in the environment had been removed through media changes, many of these effects had been reversed, or were no longer significantly different to SLA Ti. Whilst hMSC responses on $\mathrm{CHX}$-HMP coatings were different to those on SLA Ti, they were more similar than those seen with the $\mathrm{CHX}_{(\mathrm{aq})}$ control. This suggests that the slower $\mathrm{CHX}_{(\mathrm{aq})}$ release from the $\mathrm{CHX}$-HMP coatings may induce fewer adverse effects on cell metabolism than the $\mathrm{CHX}_{(\mathrm{aq})}$ control, which showed increased ROS generation, mitochondrial permeabilisation and apoptosis.

Whilst the metabolomic effects appeared to be transient, reduced or minimal osteocalcin, osteopontin and phosphate deposits within hMSCs on the CHX-HMP coatings relative to SLA Ti persisted. Interestingly, Kotsakis et al. [53] reported no effect on osteocalcin activity at 3 and 5 days in murine osteoblasts following a 20-second exposure to a much higher concentration of $\mathrm{CHX}_{(\mathrm{aq})}(0.0672 \%)$ than that released by the CHX-HMP coatings in this work over a number of hours. This again shows that $\mathrm{CHX}_{(\mathrm{aq})}$ toxicity to hMSCs is a function of concentration and exposure duration. Both of these parameters would need to be considered when further developing the CHX-HMP coating.

\section{Conclusion}

Maximising adherence of hMSCs whilst minimising that of microorganisms is a key challenge of implant surface development [16, 20]. The data presented here indicate that the CHX-HMP-100 coating on SLA Ti had the capability to reduce biofilm formation by relevant oral microorganisms, and simultaneously allowed adhesion, growth and proliferation of hMSCs. CHX-HMP-100 appeared better tolerated by the hMSCs than CHX-HMP-200. Whilst CHXHMP-100 did induce adverse effects, network predictions from metabolomic analyses suggested that, if hMSCs were able to survive the initial $\mathrm{CHX}_{(\mathrm{aq})}$ insult, they were able to recover some function and continue to proliferate and even commence osteoblastic differentiation once the $\mathrm{CHX}_{(\mathrm{aq})}$ was removed. As such, hMSCs may be able to tolerate the CHX-HMP-100 coating. Given its antibiofilm effects, this coating could merit further investigation and optimisation as a potential implant coating with the aim of addressing early dental implant infection and failure.

\section{Data availability}

Data freely available from this link: data.bris Data from Garner et al 2020 (06-2020).

Acknowledgements Thanks are due to Dr Lindsay Dutton, Dr Jane Brittan, Mrs Carol-Anne Smith and Mrs Margaret Mullin for their assistance and support with various aspects of laboratory work.

Author contributions SJG performed experimental work and drafted the manuscript. MEB, AHN and MJD advised on experimental design, analysis and manuscript refinement. 
Funding This work was supported by the Medical Research Council via a Clinical Research Training Fellowship to SG [MR/N001362/1].

\section{Compliance with ethical standards}

Conflict of interest MEB is named inventor on a patent describing the CHX-HMP material and director and shareholder of a spin-out company formed to commercialise this and related materials. Other authors: Not applicable

Publisher's note Springer Nature remains neutral with regard to jurisdictional claims in published maps and institutional affiliations.

Open Access This article is licensed under a Creative Commons Attribution 4.0 International License, which permits use, sharing, adaptation, distribution and reproduction in any medium or format, as long as you give appropriate credit to the original author(s) and the source, provide a link to the Creative Commons license, and indicate if changes were made. The images or other third party material in this article are included in the article's Creative Commons license, unless indicated otherwise in a credit line to the material. If material is not included in the article's Creative Commons license and your intended use is not permitted by statutory regulation or exceeds the permitted use, you will need to obtain permission directly from the copyright holder. To view a copy of this license, visit http://creativecommons. org/licenses/by/4.0/.

\section{References}

1. Le Guéhennec L, Soueidan A, Layrolle P, Amouriq Y. Surface treatments of titanium dental implants for rapid osseointegration. Dent Mater. 2007;23:844-54. https://doi.org/10.1016/j.dental. 2006.06.025.

2. Camps-Font O, Figueiredo R, Valmaseda-Castellón E, GayEscoda C. Postoperative infections after dental implant placement: Prevalence, clinical features, and treatment. Implant Dent. 2015;24:713-9. https://doi.org/10.1097/ID.0000000000000325

3. Gynther GW, Köndell PÅ, Moberg LE, Heimdahl A. Dental implant installation without antibiotic prophylaxis. Oral Surg Oral Med Oral Pathol Oral Radio Endod. 1998;85:509-11. https://doi. org/10.1016/S1079-2104(98)90281-5.

4. Esposito M, Hirsch JM, Lekholm U, Thomsen P. Biological factors contributing to failures of osseointegrated oral implants. (I). Success criteria and epidemiology. Eur J Oral Sci. 1998;106:527-51. https://doi.org/10.1046/j.0909-8836.t01-2-.x.

5. Zhao L, Chu PK, Zhang Y, Wu Z. Antibacterial coatings on titanium implants. J Biomed Mater Res Part B Appl Biomater. 2009;91B:470-80. https://doi.org/10.1002/jbm.b.31463.

6. Chrcanovic B, Albrektsson T, Wennerberg A. Diabetes and oral implant failure: a systematic review. J Dent Res. 2014;93:859-67. https://doi.org/10.1177/0022034514538820.

7. Jepsen S, Berglundh T, Genco R, Aass AM, Demirel K, Derks J. et al. Primary prevention of peri-implantitis: Managing periimplant mucositis. J Clin Periodontol. 2015;42:S152-7. https:// doi.org/10.1111/jcpe.12369.

8. Matthes R, Duske K, Kebede TG, Pink C, Schluter R, von Woedtke T. et al. Osteoblast growth, after cleaning of biofilmcovered titanium discs with air-polishing and cold plasma. J Clin Periodontol. 2017;44:672-80. https://doi.org/10.1111/jcpe.12720.

9. Camps-Font O, Gay-Escoda C, Martín-Fatás P, Clé-Ovejero A. Postoperative infections after dental implant placement: Variables associated with increased risk of failure. J Periodontol. 2018;89:1165-73. https://doi.org/10.1002/JPER.18-0024.
10. Quirynen M, de Soete M, Van Steenberghe D. Infectious risks for oral implants: a review of the literature. Clin Oral Implants Res. 2002;13:1-19. https://doi.org/10.1034/j.1600-0501.2002.130101.x.

11. Dal'Agnol CZ, Stefenon L, van De Sande FH, Bona AD, Cenci MS, Webber B. et al. Microcosm biofilm formation on titanium surfaces. Mater Res. 2015;18:677-82. https://doi.org/10.1590/ 1516-1439.346814.

12. Di Giulio M, Traini T, Sinjari B, Nostro A, Caputi S, Cellini L. Porphyromonas gingivalis biofilm formation in different titanium surfaces, an in vitro study. Clin Oral Implants Res. 2016;27:918-25. https://doi.org/10.1111/clr.12659.

13. Zitzmann NU, Berglundh T. Definition and prevalence of periimplant diseases. J Clin Periodontol. 2008;35:286-91. https://doi. org/10.1111/j.1600-051X.2008.01274.x.

14. Atieh MA, Alsabeeha NHM, Faggion CM, Duncan WJ. The frequency of peri-implant diseases: a systematic review and metaanalysis. J Periodontol. 2012;84:1586-98. https://doi.org/10.1902/ jop.2012.120592.

15. Derks J, Tomasi C. Peri-implant health and disease. A systematic review of current epidemiology. J Clin Periodontol. 2015;42: S158-71. https://doi.org/10.1111/jcpe.12334.

16. Smeets R, Stadlinger B, Schwarz F, Beck-Broichsitter B, Jung O, Precht C. et al. Impact of dental implant surface modifications on osseointegration. Biomed Res Int. 2016;2016:6285620-16. https://doi.org/10.1155/2016/6285620.

17. Park J, Tennant M, Walsh LJ, Kruger E. Is there a consensus on antibiotic usage for dental implant placement in healthy patients? Aust Dent J. 2018;63:25-33. https://doi.org/10.1111/adj.12535.

18. Esposito M, Grusovin MG, Worthington HV. Interventions for replacing missing teeth: antibiotics at dental implant placement to prevent complications (Review). Cochrane Database Syst Rev. 2013;121:800.

19. Hickok NJ, Shapiro IM, Chen AF. The impact of incorporating antimicrobials into implant surfaces. J Dent Res. 2018;97:14-22. https://doi.org/10.1177/0022034517731768.

20. Grischke J, Eberhard J, Stiesch M. Antimicrobial dental implant functionalization strategies-A systematic review. Dent Mater J. 2016;35:545-58. https://doi.org/10.4012/dmj.2015-314.

21. Wood NJ, Jenkinson HF, Davis SA, Mann S, O'Sullivan DJ, Barbour ME. Chlorhexidine hexametaphosphate nanoparticles as a novel antimicrobial coating for dental implants. J Mater Sci Mater Med. 2015;26:201 https://doi.org/10.1007/s10856-015-5532-1.

22. Barbour ME, Maddocks SE, Wood NJ, Collins AM. Synthesis, characterization, and efficacy of antimicrobial chlorhexidine hexametaphosphate nanoparticles for applications in biomedical materials and consumer products. Int J Nanomed. 2013;8:3507-19. https://doi.org/10.2147/IJN.S50140.

23. Bellis CA, Nobbs AH, O'Sullivan DJ, Holder JA, Barbour ME. Glass ionomer cements functionalised with a concentrated paste of chlorhexidine hexametaphosphate provides dose-dependent chlorhexidine release over at least 14 months. J Dent. 2016;45:53-8. https://doi.org/ 10.1016/j.jdent.2015.12.009.

24. Barbour ME, Maddocks SE, Grady HJ, Roper JA, Bass MD, Collins AM. et al. Chlorhexidine hexametaphosphate as a wound care material coating: antimicrobial efficacy, toxicity and effect on healing. Nanomedicine. 2016;11:2049-57. https://doi.org/10.2217/nnm-2016-0084.

25. Bellis CA, Addison O, Nobbs AH, Duckworth PF, Holder JA, Barbour ME. Glass ionomer cements with milled, dry chlorhexidine hexametaphosphate filler particles to provide long-term antimicrobial properties with recharge capacity. Dent Mater. 2018;34:1717-26. https://doi.org/10.1016/j.dental.2018.09.003.

26. Garner SJ, Nobbs AH, McNally LM, Barbour ME. An antifungal coating for dental silicones composed of chlorhexidine nanoparticles. J Dent. 2015;43:362-72. https://doi.org/10.1016/j.jdent.2014.12.005.

27. Millhouse E, Jose A, Sherry L, Lappin DF, Patel N, Middleton AM. et al. Development of an in vitro periodontal biofilm model 
for assessing antimicrobial and host modulatory effects of bioactive molecules. BMC Oral Health. 2014;14:80. https://doi.org/10. 1186/1472-6831-14-80.

28. Subramani K, Jung RE, Molenberg A, Hammerle CHF. Biofilm on dental implants: a review of the literature. Int J Oral Maxillofac Implants. 2009;24:616-26.

29. Leonhardt $\AA$, Renvert S, Dahlén G. Microbial findings at failing implants. Clin Oral Implants Res. 1999;10:339-45. https://doi.org/ 10.1034/j.1600-0501.1999.100501.x.

30. Mombelli A. Microbiology and antimicrobial therapy of periimplantitis. Periodontol 2000. 2002;28:177-89. https://doi.org/10. 1034/j.1600-0757.2002.280107.x.

31. Charalampakis G, Belibasakis GN. Microbiome of peri-implant infections: Lessons from conventional, molecular and metagenomic analyses. Virulence. 2015;6:183-7. https://doi.org/10.4161/ 21505594.2014.980661.

32. Duckworth PF. Chlorhexidine-phosphate salts in wound care; the development and testing of antimicrobial functionalised materials. $\mathrm{PhD}$ thesis, University of Bristol, Bristol, UK, 2017.

33. Albrektsson T, Wennerberg A. The impact of oral implants-Past and future, 1966-2042. J Can Dent Assoc. 2005;71:327.

34. Dohan Ehrenfest DM, Del Corso M, Kang BS, Leclercq P, Mazor Z, Horowitz RA, et al. Identification card and codification of the chemical and morphological characteristics of 62 dental implant surfaces. Part 3: sand-blasted/acid-etched (SLA type) and related surfaces (Group 2A, main subtractive process). POSEIDO J. 2014;2:37-55.

35. Sezin M, Croharé L, Ibañez JC. Microscopic study of surface microtopographic characteristics of dental implants. Open Dent J. 2016;10:139-47. https://doi.org/10.2174/1874210601610010139.

36. Bok WM, Kim SY, Lee SJ, Shin GS, Park JM, Lee MH. Surface characteristics and bioactivation of sandblasted and acid-etched (SLA) Ti-10Nb-10Ta alloy for dental implant. Int J Precis Eng Manuf. 2015;16:2185-92. https://doi.org/10.1007/s12541-015-0281-0.

37. Buser D, Broggini N, Wieland M, Schenk RK, Denzer AJ, Cochran DL. et al. Enhanced bone apposition to a chemically modified SLA titanium surface. J Dent. 2004;83:529-33. https:// doi.org/10.1177/154405910408300704.

38. Buser D, Nydegger T, Oxland T, Cochran DL, Schenk RK, Hirt HP. et al. Interface shear strength of titanium implants with a sandblasted and acid-etched surface: a biomechanical study in the maxilla of miniature pigs. J Biomed Mater Res. 1999;45:75-83. https://doi.org/10.1002/(SICI)1097-4636(199905)45:2<75::AIDJBM1>3.0.CO;2-P.

39. Buser D, Nydegger T, Hirt HP, Cochran DL, Nolte LP. Removal torque values of titanium implants in the maxilla of miniature pigs. Int J Oral Maxillofac Implants. 1998;13:611-9.

40. Bosshardt DD, Chappuis V, Buser D. Osseointegration of titanium, titanium alloy and zirconia dental implants: current knowledge and open questions. Periodontol 2000. 2017;73:22-40. https://doi.org/10.1111/prd.12179

41. Albrektsson T, Wennerberg A. Oral implant surfaces: Part 1-review focusing on topographic and chemical properties of different surfaces and in vivo responses to them. Int J Prosthodont. 2004;17:536-43.

42. Andrukhov O, Huber R, Shi B, Berner S, Rausch-Fan X, Moritz A. et al. Proliferation, behavior, and differentiation of osteoblasts on surfaces of different microroughness. Dent Mater. 2016;32:1374-84. https://doi.org/10.1016/j.dental.2016.08.217.

43. Dohan Ehrenfest DM, Coelho PG, Kang BS, Sul YT, Albrektsson T. Classification of osseointegrated implant surfaces: Materials, chemistry and topography. Trends Biotechnol. 2010;28:198-206. https://doi.org/10.1016/j.tibtech.2009.12.003.

44. Socransky SS, Haffajee AD. Dental biofilms: difficult therapeutic targets. Periodontol 2000. 2002;28:12-55. https://doi.org/10.1034/ j.1600-0757.2002.280102.x.
45. Seneviratne CJ, Leung KCF, Wong CH, Lee SF, Li X, Leung PC. et al. Nanoparticle-encapsulated chlorhexidine against oral bacterial biofilms. PLoS One. 2014;9:e103234. https://doi.org/10. 1371/journal.pone.0103234.

46. Vilarrasa J, Delgado LM, Galofre M, Alvarez G, Violant D, Manero JM. et al. In vitro evaluation of a multispecies oral biofilm over antibacterial coated titanium surfaces. J Mater Sci Mater Med. 2018;29:164 https://doi.org/10.1007/s10856-018-6168-8.

47. Tamura N, Ochi M, Miyakawa H, Nakazawa F. Analysis of bacterial flora associated with peri-implantitis using obligate anaerobic culture technique and 16S rDNA gene sequence. Int J Oral Maxillofac Implants. 2014;28:1521-9. https://doi.org/10.11607/jomi.2570.

48. Kommerein N, Stumpp SN, Musken M, Ehlert N, Winkel A, Haussler S. et al. An oral multispecies biofilm model for high content screening applications. PLoS One. 2017;12:e0173973. https://doi.org/10.1371/journal.pone.0173973.

49. Vale RD. The molecular motor toolbox for intracellular transport. Cell. 2003;112:467-80. https://doi.org/10.1016/S00928674(03)00111-9.

50. Dalby MJ, García AJ, Salmeron-Sanchez M. Receptor control in mesenchymal stem cell engineering. Nat Rev Mater 2018;3. https://doi.org/10.1038/natrevmats.2017.91.

51. Zhao G, Zinger O, Schwartz Z, Wieland M, Landolt D, Boyan BD. Osteoblast-like cells are sensitive to submicron-scale surface structure. Clin Oral Implants Res. 2006;17:258-64. https://doi. org/10.1111/j.1600-0501.2005.01195.x.

52. Giannelli M, Chellini F, Margheri M, Tonelli P, Tani A. Effect of chlorhexidine digluconate on different cell types: a molecular and ultrastructural investigation. Toxicol Vitr. 2008;22:308-17. https://doi.org/10.1016/j.tiv.2007.09.012

53. Kotsakis GA, Lan C, Barbosa J, Lill K, Chen R, Rudney J. et al. Antimicrobial agents used in the treatment of peri-implantitis alter the physicochemistry and cytocompatibility of titanium surfaces. J Periodontol. 2016;87:809-19. https://doi.org/10.1902/jop.2016.150684.

54. Schmidlin PR, Imfeld T, Sahrmann P, Tchouboukov A, Weber FE. Effect of short-time povidone-iodine application on osteoblast proliferation and differentiation. Open Dent J. 2009;3:208-12. https://doi.org/10.2174/1874210600903010208.

55. Ly JD, Grubb DR, Lawen A. The mitochondrial membrane potential $(\delta \psi \mathrm{m})$ in apoptosis; an update. Apoptosis. 2003;8:115-28. https://doi.org/10.1023/A:1022945107762.

56. Vörös P, Dobrindt O, Perka C, Windisch C, Matziolis G, Röhner E. Human osteoblast damage after antiseptic treatment. Int Orthop. 2014;38:177-82. https://doi.org/10.1007/s00264-013-2107-y.

57. Hidalgo E, Dominguez C. Mechanisms underlying chlorhexidineinduced cytotoxicity. Toxicol Vitr. 2001;15:271-6. https://doi.org/ 10.1016/S0887-2333(01)00020-0.

58. Salimi A, Alami B, Pourahmad J. Analysis of cytotoxic effects of chlorhexidine gluconate as antiseptic agent on human blood lymphocytes. J Biochem Mol Toxicol 2017. https://doi.org/10. $1002 / j b t .21918$.

59. Roskoski R. ERK1/2 MAP kinases: structure, function, and regulation. Pharm Res. 2012;66:105-43. https://doi.org/10.1016/j. phrs.2012.04.005.

60. Zambon JJ, Slots J, Genco RJ. Serology of oral Actinobacillus actinomycetemcomitans and serotype distribution in human periodontal disease. Infect Immun. 1983;41:19-27.

61. Al-Radha ASD, Pal A, Pettemerides AP, Jenkinson HF. Molecular analysis of microbiota associated with peri-implant diseases. J Dent. 2012;40:989-98. https://doi.org/10.1016/j.jdent.2012.08.006.

62. Milsom SE, Sprague SV, Dymock D, Weightman AJ, Wade WG. Rapid differentiation of Prevotella intermedia and P. nigrescens by $16 \mathrm{~S}$ rDNA PCR-RFLP. J Med Microbiol. 1996;44:41-43. https://doi.org/10.1099/00222615-44-1-41. 